
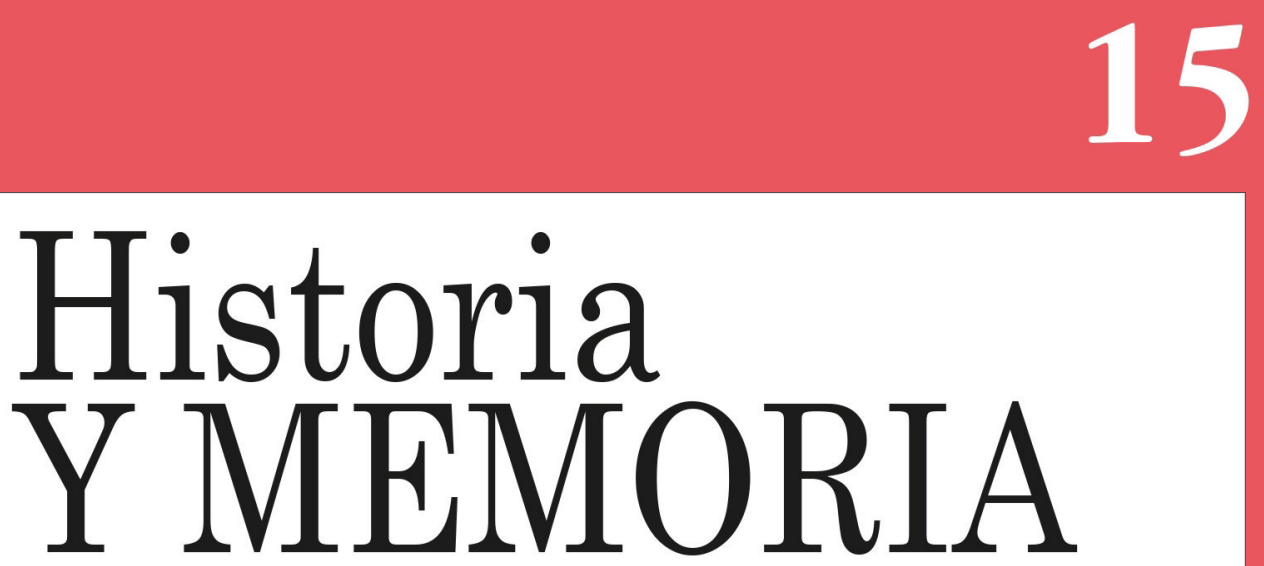

ISSN: 2027-5137 Julio - Diciembre, Año 2017 - Tunja, Colombia

Tergiversaciones sobre la batalla de Cachirí y el restablecimiento del régimen virreinal neogranadino (1816) https://doi.org/10.19053/20275137.n15.2017.4922

Luis Rubén Pérez Pinzón orcid.org/0000-0003-0387-6035

Páginas: 73-105

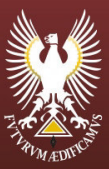




\title{
Tergiversaciones sobre la batalla de Cachirí y el restablecimiento del régimen virreinal neogranadino (1816)*
}

\author{
Luis Rubén Pérez Pinzón ${ }^{1}$ \\ Universidad Autónoma de Bucaramanga - Colombia
}

Recepción: 26/06/2016

Evaluación: 15/01/2017

Aprobación: 13/03/2017

Artículo de Investigación e Innovación.

https://doi.org/10.19053/20275137.n15.2017.4922

\section{Resumen}

Acontecimientos históricos como la batalla de Cachirí (1816) demuestran que no hay unidad narrativa ni explicativa entre las diferentes generaciones que han estudiado la historia nacional ni entre las clases sociales que promueven discursos acordes a sus imaginarios. El artículo describe cómo han variado las explicaciones entre la historia oficial, la memoria popular y el patrimonio monumental de las élites regionales acerca de la batalla que decidió el triunfo del ejército expedicionario de reconquista. Para ello, son analizados los discursos históricos que caracterizan la versión oficial de lo acontecido, se contrastan con las representaciones históricas regionales y nacionales, así como se destacan los vacíos y

* Artículo de Investigación resultado del proyecto interinstitucional entre la Alcaldía del Municipio de Piedecuesta, la Universidad Autónoma de Bucaramanga y la Universidad Industrial de Santander titulado: «Plan Decenal de Cultura del Municipio de Piedecuesta (Santander, Colombia) 2017-2026». Proyecto registrado a nombre del grupo de investigación «Pensamiento Sistémico» ante la Dirección de Investigaciones de la Universidad Autónoma de Bucaramanga como parte de la convocatoria bienal interna de investigación 2015-2016.

1 Doctor en Historia (AIU, USA). Integrante de los grupos de investigación: «Pensamiento Sistémico» - UNAB, y «Políticas, Sociabilidades y Representaciones Histórico-Educativas» - UIS. Líneas de investigación: Pensamiento tecnológico - UNAB, y Patrimonio Cultural - UIS. Publicaciones recientes: «El General José Santos: Héroe y villano de la Regeneración», en Una familia Santos de Santander y Colombia, coord. Armando Martínez (Bucaramanga: El libro total, 2013). lperez14@unab.edu.co iD orcid.org/0000-0003-0387-6035 
anacronismos de esas historias y representaciones desde la memoria popular. Todo lo cual conlleva a identificar las tergiversaciones nacionales que coexisten sobre un mismo hecho (la batalla de Cachirí) y un mismo personaje histórico (Custodio García Rovira) en la Nueva Granada de 1816.

Palabras clave: Historia, independencia, reconquista, monumento, batalla de Cachirí.

\section{Distortions on the Battle of Cachiri and the Reestablishment of the Viceroyal Regime of the New Granada (1816)}

\section{Summary}

Historical events such as the battle of Cachirí (1816) demostrate that there is no narrative or explicative unity between different generations that have studied the national history, nor among the social classes that promote discourses based on their different imaginaries. This article describes the variation in explanations between official history, popular memory and monument heritage of the regional elite, regarding the battle that defined the triumph of the expeditionary army of the Reconquista. For this purpose, we analyze historical discourses that characterize the official version of the events taken place, and contrast them with the regional and national historical representations. At the same time as we highlight the silences and anachronisms of these histories and representations from the point of view of popular memory. All of this leads to identifying the different national distortions that coexist regarding one event (the battle of Cachirí) and one historical character (Custodio García Rovira) in the New Granada of 1816.

Key Words: History, Independence, Reconquista, Monument, Battle of Cachirí. 


\section{Déformations à propos de la bataille de Cachirí et du rétablissement du régime vice-royal néogrenadin}

(1816)

\section{Résumé}

Des événements historiques comme la bataille de Cachirí (1816) montrent que ni les différentes générations ayant étudié l'histoire nationale ni les classes sociales qui formulent des discours fidèles à leur imaginaires ne partagent d'unité narrative ou explicative. Cet article décrit comment ont changé les explications entre l'histoire officielle, la mémoire populaire et le patrimoine monumental des élites régionales à propos de la bataille qui a décidé la victoire de l'armée expéditionnaire de reconquête. Pour ce faire, nous analysons les discours historiques qui caractérisent la version officielle; ensuite, nous les confrontons avec les représentations historiques régionales et nationales; puis nous soulignons les vides et les anachronismes de ces histoires et de ces représentations à partir de la mémoire populaire. Tout ceci nous mène à identifier les déformations nationales qui coexistent sur un même événement (la bataille de Cachirí) et un même personnage (Custodio García Rovira) dans la Nouvelle Grenade de 1816.

Mots-clés: Histoire, indépendance, reconquête, monument, bataille de Cachirí.

\section{Introducción}

La construcción del imaginario de Colombia y los colombianos como Estado Nación ha estado asociado con los acontecimientos históricos que marcaron los hitos fundantes de la actual República ${ }^{2}$. Para reafirmar esa identidad, las generaciones de élites políticas e intelectuales encargadas de conmemorar el quincuagésimo aniversario, el centenario y el bicentenario de creación y reafirmación del proyecto nacional colombiano optaron por la construcción de relatos de conmemoración y programas de celebración, en los cuales han primado el

2 Andrés Castiblanco, «El bicentenario en Colombia. Memoria, patrimonio y territorio", Historia Y MEMORIA, n 1 (2010): 113-133. 
heroísmo bélico revolucionario ${ }^{3}$ antes que el discurso civilista e independentista ${ }^{4}$ de los republicanos ilustrados ${ }^{5}$.

Las conmemoraciones de las fuerzas armadas de Colombia son ejemplo de esos imaginarios al realizarse majestuosos desfiles militares en $1910^{6}$ y agresivas campañas comunicacionales desde $2010^{7}$. Con ellas han buscado exaltar las magnas acciones de sus generales y «héroes» en los campos de batalla, minimizando el papel de precursores, caudillos, mártires, etc., que caracterizaron las acciones insurgentes de los diputados, gobernantes, legisladores ${ }^{8}$, constitucionalistas ${ }^{9}$, etc., desde la primera república (1810-1816).

Esos desfiles militares fueron institucionalizados en el país al conmemorarse cada día de la independencia nacional (20 de julio) con monumentales revistas en honor a la fuerza armada -policial del país, así como el día de liberación nacional (7 de agosto) estuvo asociado con el reconocimiento y exaltación a las fuerzas armadas- militares, y en particular con la conmemoración del "día del ejército nacional» frente a los monumentos y héroes militares. Tradición con la que se minimizó el papel, accionar y protagonismo que tuvieron

$3 \quad$ Abel Fernando Martínez Martín y Andrés Ricardo Otálora, «Antonio Ricaurte. La creación de la imagen de un héroe niño 1830-1881», Historia Y MEMORIA, n 4 (2012): 13-44.

4 Josep Fontana, «En torno al significado de la independencia», Historia $Y$ MEMORIA, $\mathrm{n}^{\circ} 2$ (2011): 11-32.

5 Luis Pérez, Historia bicentenaria de un día de revolución (Bucaramanga: Universidad Industrial de Santander, 2007).

6 Abel Fernando Martínez Martín y Andrés Ricardo Otálora, «Patria y Madre Patria. Las fiestas centenarias de 1910 y 1911 en Tunja», Historia Y MEMORIA, n 5 (2012): 115-143.

7 Luis Pérez, "¿Qué dejó a la historiografía regional el Bicentenario de la Independencia de Colombia? La resignificación del Socorro y los socorranos», Anuario de Historia Regional y de las Fronteras 16, n 1 (2011): 331-352.

8 Jorge Tomás Uribe Ángel, «Independencia, historia y derecho», Historia $Y$ MEMORIA, $\mathrm{n}^{\circ} 2$ (2011): 125-143.

9 Víctor Uribe Urán, «Insurgentes de Provincia: Tunja, Nueva Grananda y el Constitucionalismo en el Mundo Hispánico en la década de 1810», Historia Y MEMORIA, ${ }^{\circ} 5$ (2012): 17-48. 
los civiles letrados ${ }^{10}$, los estudiantes mártires ${ }^{11}$, los criollos insurrectos exaltados por las bebidas embriagantes ${ }^{12}$, las organizaciones armadas irregulares ${ }^{13}$, así como las comunidades parroquiale ${ }^{14}$ en el triunfo y consolidación de la emancipación política de 1810 como de la triunfante «campaña libertadora $»^{15}$ de 1819.

Tales prácticas y convicciones durante doscientos años de vida republicana han sido asumidas como referentes necesarios para que las provincias y municipalidades ${ }^{16}$ reafirmen su origen y destino republicano a partir de los acontecimientos bélicos asociados con la gesta libertadora ${ }^{17}$. Por ejemplo, los habitantes de El Socorro defienden que el movimiento comunero fue el germen y cuna de la libertadora americana (1781) ${ }^{18}$; los habitantes de Cartagena y Mompox reclaman ser los primeros en independizarse (1811) y resistir el embate de la reconquista española (1815); las provincias del piedemonte llanero se enorgullecen de ser los protagonistas de gestas como la batalla de Vargas (1819); la provincia de Charalá y el Socorro con el martirio de sus mujeres

10 Armando Martínez Garnica, «José Joaquín Camacho y su influencia en la Constitución de la Provincia de Tunja (1811)», Historia Y MEMORIA, n 5 (2012): 73-111.

11 Antonio Cacua Prada, Custodio García Rovira El estudiante mártir (Bogotá: Plaza \& Janes, 1983).

12 Roger Pita, «El consumo de bebidas embriagantes durante el proceso de Independencia de Colombia; aliento, festejo y conspiración", Historia Y MEMORIA, $\mathrm{n}^{\circ} 7$ (2013): 227-268.

13 Pérez, “¿Qué dejó a la historiografía...», 331-352.

14 Alonso Valencia, «Indígenas, plebe, sectores populares y afrodescendientes en la independencia de la gobernación de Popayán», Historia Y MEMORIA, ${ }^{\circ} 1$ (2010): 87-112.

15 Luis Pérez, Historiar la muerte II. Representaciones sociopolíticas sobre el buen "morir por la patria" entre los revolucionarios de Colombia (Bucaramanga: Universidad Industrial de Santander, 2013).

16 Edda Samudio, «La experiencia juntista en Mérida (Venezuela) 1808-1811», Historia Y MEMORIA, $\mathrm{n}^{\circ} 1$ (2010): 35-53.

17 Juan Manuel Robayo, "Reflexiones en torno al impacto de la Patria Boba. La independencia de Tunja y su provincia 1810-1815», Historia Y MEMORIA, $\mathrm{n}^{\circ} 1$ (2010): 11-33.

18 Luis Pérez, Giros historiográficos sobre la Historia [Turística] del Socorro. (Bucaramanga: L. R. Pérez Pinzón, 2015). 
heroínas ${ }^{19}$, el genocidio de la batalla de Pienta ${ }^{20}$ y el accionar de las guerrillas patriotas reclaman ser los protagonistas olvidados ${ }^{21}$ del triunfo libertador en la batalla de Boyacá (1819), la cual llenó de gloria solo a la provincia de Tunja. A lo cual se suman las batallas asociadas con las guerras civiles del siglo XIX, cuyo último y más cruel referente fue la batalla de Palonegro (1900) ${ }^{22}$, a partir de la cual se redefinió la importancia geoestratégica que han tenido las capitales de los Departamentos de Santander y Norte de Santander ${ }^{23}$.

Sin embargo, en los relatos bélicos de la historia nacional republicana no se evidencia el interés por apropiarse, rememorar, conmemorar o exaltar acontecimientos como la batalla de Cachirí (1816), caracterizada por ser el primer combate de resistencia y liberación unificada contra el ejército expedicionario español que reestableció el régimen virreinal neogranadino desde 1816 hasta $1819^{24}$.

Lo acontecido en Cachirí fue la primera acción de un ejército conformado por batallones provenientes de las principales provincias del país en nombre de la Unión de una república, una constitución, un gobierno y una federación, así como fue la batalla más cuestionada, vergonzosa, destructiva y despreciada por los historiadores, gobernantes y generales de las siguientes generaciones al representar la mayor derrota, improvisación y sacrificio de tropas y pertrechos entre todos los actos de formación de la República. Especialmente entre los gobernantes y militares oriundos de las provincias de Soto,

19 Joan Pagés y Edda Sant, «¿Por qué las mujeres son invisibles en la enseñanza de la historia?», Historia Y MEMORIA, n 3 (2011): 129-146.

20 Álvaro Sarmiento, La batalla perdida (Bucaramanga: El libro total, 2010).

21 Emilio Arenas, La Guaneña La epopeya del Estado Libre e Independiente del Socorro (Bucaramanga: El libro total, 2010).

22 Luis Pérez, «El General José Santos: Héroe y villano de la Regeneración», en Una familia Santos de Santander y Colombia, coord. Armando Martínez (Bucaramanga: El libro total, 2013), 113-398.

23 Luis Pérez, Narrativas del último Postconflicto en Colombia. Antología literaria de la Guerra de los Mil Días (1899-1902) (Bucaramanga: L. R. Pérez Pinzón, 2015).

24 Rebecca Earle, Spain and the Independence of Colombia, 1810-1825 (Chicago: University of Exeter Press, 1999). 
Pamplona y Ocaña que participaron o coexistieron con los acontecimientos ${ }^{25}$.

En diciembre de 1815, la caída de la primera república federal y unitaria neogranadina ${ }^{26}$, constituida un año antes con la invasión y sometimiento del Estado de Cundinamarca, era inevitable. Desde la perspectiva del primer relato sistemático de la historia de Colombia propuesto por el ministro José Manuel Restrepo, acorde al discurso «bolivarista» de la segunda república (1819-1831) ${ }^{27}$, se consideraba que: Cartagena antes de ser invadida por el Ejército expedicionario no encontraba sentido a su pertenencia a la federación al ser útil para aportar "auxilios» pero no tenía apoyo con batallones de las provincias del interior para defender las fronteras marítimas; el poder ejecutivo general no contaba con unidad ni energía; el ejército unitario formado por S. Bolívar para invadir Santafé había sido fragmentado en tres débiles divisiones de defensa (Cúcuta, Casanare y Popayán); los ministros de guerra y hacienda existían en el papel mientras que los gobernadores y capitanes generales de cada provincia actuaban con absoluta independencia de la autoridad central nacional; las elites capitalinas conspiraban para derrocar o presionar la caída de los republicanos en el poder, y en especial, los jefes de gobierno encabezados por Camilo Torres ante la alarma de invasión «no conmovieron los pueblos ni tomaron aquellas medidas vigorosas que exigen los grandes peligros» ${ }^{28}$.

Los héroes y mártires del sitio y batalla de Cartagena fueron presentados por José Manuel Restrepo ante la primera generación de ciudadanos colombianos como una generación

25 Pastor Virviescas, «Del grito victorioso de “Firmes Cachirí!” a la caída estrepitosa de un mito santandereano», Periódico 15 Unab, Bucaramanga, 15 de marzo de 2016, 4-5.

26 Justo Cuño, «Lo real y lo imaginario en la construcción en la primera etapa de la Republica colombiana», Historia Y MEMORIA, n² 2 (2011): 33-52.

27 Álvaro Acevedo y Carlos Villamizar, «El último Bolívar: renuncia y retiro del ejercicio del poder (1829-1830) entre la autoridad y la legalidad», Historia $Y$ MEMORIA, $\mathrm{n}^{\circ} 11$ (2015): 213-239.

28 José Manuel Restrepo, Historia de la Revolución de República de Colombia en la América Meridional (Besanzon: Imprenta de José Jacquin, 1858), 336. 
de «desgraciados»" ${ }^{29}$ derrotados que no debían olvidarse porque: «Su constancia y sufrimiento llegaron a un grado heroico. Pereciendo diariamente por centenares, sin víveres y con muy pocas esperanzas de conseguirlos, comiendo hasta los animales más inmundos, jamás hubo quien propusiera rendirse ni hacer la paz con los tiranos, origen de todos sus males» ${ }^{30}$.

La misma consideración no fue sugerida ni expresada en lo concerniente a las víctimas de la batalla de Cachirí. Los integrantes del Ejército de la Unión que fueron vencidos en ella también cayeron bajo el sitio y la superioridad bélica realista, no tuvieron víveres ni logística, así como padecieron las consecuencias de las funestas condiciones climáticas de la alta montaña. No obstante, la historiografía republicana a la par de exaltar el martirio cartagenero promovió un relato sobre lo acontecido en Cachirí caracterizado por la sospecha y los desaciertos de comandantes y oficiales nefastos, soldados inexpertos, gobernantes traidores y reclutas cobardes. De allí que autores como J. Restrepo optaron por interpretar lo acontecido desde la perspectiva de las historias y memorias militares de los oficiales españoles desde su condición de testigos presenciales, de la siguiente manera:

Según los vencedores, el yerro de capital de Robira en esta acción fue haber querido hacer con tropas bisoñas la defensa por escalones, cuando solo es dado hacerla con las que son aguerridas (...) Las consecuencias de la pérdida de esta batalla fueron las más funestas para la Nueva Granada. Hasta Santafé no había tropa alguna, y en la capital solo existían débiles cuerpos ${ }^{31}$.

Desde entonces, la historia de sucesos como la batalla de Cachirí se ha constituido en un relato que ha sido tergiversado en cuanto a sus causas y consecuencias para la historia general del país, así como ha sido adecuado a través del tiempo acorde a las coyunturas sociopolíticas e ideológicas de cada localidad.

29 Edwin Monsalvo, «Ciudadanía, vecindad y sufragio en Cartagena 1810-1834», Historia Y MEMORIA, n 6 (2013): 171-204.

30 Restrepo, Historia de la Revolución..., 384.

31 Restrepo, Historia de la Revolución..., 391-392. 
La historia oficial divulgada en los artículos, libros y manuales de textos de los académicos capitalinos ${ }^{32}$, desde finales del siglo XIX dejó de coincidir y ajustarse a la memoria popular de las comunidades provinciales, quienes ante la vergonzante derrota y fracaso de sus "paisanos» promovida por el discurso oficial han optado por reconocer, a través de esas vicisitudes al heroísmo y martirio de patriotas comprometidos, apelando para ello a crear sus propias versiones y visiones de lo acontecido. Así, con cada conmemoración patria se han creado y promovido diversidad de cantos, placas, estatuas y monumentos para sus mártires con los que se realzan sus gestas heroicas y la adopción de una interpretación "republicana», compasiva y tolerante con sus fracasos.

Esa dualidad ha sido profundizada por las comunidades campesinas donde acontecieron los hechos bélicos al construir una memoria popular compuesta por mitos, leyendas y anécdotas sobre lo acontecido que reinterpreta la versión centralista, agrega un carácter superior y divino a los héroes (vencedores o vencidos), así como construyen un imaginario fundacional de la República a partir de los acontecimientos y vestigios adaptados a su entorno ambiental y productivo. Dinámica de contrastes y convicciones contradictorias sobre un mismo hecho (la batalla de Cachirí) y un personaje protagónico juzgado por la historia (Custodio García Rovira) que se describe en los siguientes apartes.

\section{Convicciones desde la memoria popular de las gentes de "Cachirí»}

A la par de los acontecimientos dispuestos en los libros y publicaciones que han caracterizado la "historia patria» ${ }^{33}$ de Colombia, existen contradiscursos históricos y perspectivas anacrónicas que dan sentido a las versiones populares y la memoria local entre las comunidades rurales y urbanas que

32 Luis Pérez, «El papel bicentenario de los textos escolares en la enseñanza del día de la independencia», Revista Docencia Universitaria 9, n² 2 (2011): 125-144.

33 Alba Cardona, «Memoria, palabra y acción: La historia patria, un saber para el sentimiento», Anuario de historia regional y de las fronteras 21, $\mathrm{n}^{\circ} 2$ (2016): 19-45. 
han habitado los lugares históricos en donde acontecieron hechos bélicos como los de febrero de 1816 .

Los guías turísticos, los maestros rurales y los líderes comunales que habitan el corregimiento de Cachirí, perteneciente a la jurisdicción del Municipio de Suratá en el Departamento de Santander, han concebido y divulgado una versión de "verdad sobre lo que pasó» que resulta ser opuesta y desproporcionada en comparación con las versiones oficiales promovidas por las élites republicanas. Especialmente ante los relatos de los encargados de justificar la conmemoración del centenario y el bicentenario de la emancipación, la independencia y la liberación de los territorios que conforman la actual Colombia.

José Giovanni Lizcano Rincón como habitante de la vereda Cachirí y reconocido líder comunal al ejercer como guía turístico, historiador local y presidente de la Junta de Acción Comunal de ese mismo territorio, a la par de la conmemoración del bicentenario de la emancipación nacional (2010) promovió la exaltación como atractivo turístico y lugar de veneración histórica cada uno de los lugares asociados con la batalla de 1816. Para ello, rescató los relatos de sus abuelos y bisabuelos al paso por los lugares que evidenciaban el fragor de la batalla y los combinó con sus lecturas personales como con los hallazgos de sus exploraciones en los campos donde se cree que se enfrentaron los ejércitos de 1816, creando así un relato histórico y un guion turístico alternativo al relato tradicional. De acuerdo a su versión histórica, una roca gigantesca ha señalado durante dos siglos el sitio «exacto» donde españoles y patriotas se enfrentaron a muerte, siendo su cima desde donde el General C. García Rovira alentó a sus combatientes a permanecer "Firmes Cachirí» ante la avanzada realista hacia el interior ${ }^{34}$.

Lo acontecido sobre ese monumento natural, desde la perspectiva de J. Lizcano y de quienes guían a los visitantes en Cachirí, desencadenó un sinnúmero de acontecimientos

34 José Lizcano, «Entrevista para el programa del canal TRO: Marcando Pasos (2010)», acceso el 13 de abril de 2016, https://www.youtube.com/watch?v=aNgB0-SSlxg 
y situaciones asociados con la campaña libertadora de los siguientes años a través de la lucha armada irregular de las guerrillas provinciales, así como la conformación de un ejército popular, que con cada avance y triunfo local reclutaba o reasignaba funciones militares a los combatientes furtivos de cada parroquia. De allí que esa roca se haya constituido en un ícono local de visita obligatoria, la cual es divisada desde la cabecera urbana al permanecer izado un pabellón nacional colombiano que señala el sitio legendario donde se cree que fue consumada la primera lucha a muerte y sin cuartel por la liberación de los neogranadinos.

A partir del reconocimiento y reencuentro periódico con ese objeto patrimonial, los cachirienses insisten a sus contertulios que por ser ese el lugar donde ocurrió el teatro de operaciones y la batalla definitiva que acabó con la Patria Boba, es necesario enaltecer la memoria colectiva de los habitantes del lugar, y en especial, entender que la roca venerada representa el coraje, valor y osadía con la que el General Custodio García Rovira y sus combatientes enfrentaron la adversidad y la derrota al pedir mantenerse «Firmes». Los vecinos de Cachirí aseguran que esa frase fue pronunciada en el momento de mayor necesidad de disciplina y liderazgo al ceder las fortificaciones patriotas y que los inexpertos optaran por huir hacia los bosques y cañadas. Con lo cual, desde el relato popular se asegura que los comandantes y oficiales del ejército de la Unión se mantuvieron alentandos y liderando a sus hombres hasta los últimos momentos de la hecatombe militar, llevando su desesperación a maltratarlos con frases despreciativas como «Firmes gran carajos» ${ }^{35}$.

Sin embargo, ni ese acontecimiento ni las repercusiones de esa frase han hecho parte de las fuentes documentales de los vencedores o los vencidos ni de los testigos de la batalla de los bandos español o neogranadino. Los comandantes y oficiales españoles que obtuvieron la victoria en esa batalla, bajo la gravedad de juramento informaron a sus superiores

35 Manuel Guacaneme, «iFirmes Cachirí! (2013)», acceso el 13 de abril de 2016, https://www.youtube.com/watch?v=F1PMJtABk7k 
una versión diferente de lo acontecido, así como reclamaron el honor de rememorar su victoria al engalanar uno de sus estandartes y nombrar uno de sus batallones como "Ca chirí», exaltando así la batalla decisiva que garantizó el ingreso definitivo del ejército expedicionario de tierra firme a las provincias interiores del virreinato neogranadino. Estos hechos al ser corroborados en los informes oficiales de campaña motivaron al General Pablo Morillo a solicitar al rey Fernando VII la creación del batallón "Cachirí», rememorando así el heroísmo, los premios y ascensos obtenidos por los granaderos y cazadores españoles, así como la culminación de la campaña de pacificación de los territorios jurisdiccionales de la Audiencia de Santafé.

$\mathrm{Al}$ año siguiente, durante las batallas de pacificación de Venezuela, el batallón "Cachirí» entró nuevamente en acción al enfrentarse con el ejército realista comandado por Miguel de la Torre con los batallones de Manuel Piar durante la batalla de San Félix (Angostura, 11 de abril de 1817). Contraria a la versión de los campesinos de Cachirí, fue solo hasta ese combate cuando se escuchó y quedó registrado en los boletines de guerra que los oficiales realistas cumplieron la orden del gobernador provincial por animar y mantener la disciplina de los combatientes peninsulares, antillanos y criollos al ordenarles permanecer: «Firmes Cachirí» ${ }^{36}$.

Versión desconocida por los pedagogos e historiadores de la Provincia de Soto desde mediados del siglo XIX para quienes era incuestionable el relato legendario sobre lo acontecido en Cachirí. Según sus creencias, C. García Rovira ante la inminente derrota del ejército bajo su mando optó por un acto desesperado de valor y arrojo al mantener la unidad de sus tropas y garantizar la defensa de sus posiciones, el cual fue asumido por las generaciones posteriores como reflejo del estereotipo de valentía y heroísmo de los patriotas socorranos y pamploneses durante el siglo XIX ${ }^{37}$.

36 Rafael María Baralt y Ramón Díaz, Resumen de la historia de Venezuela desde el año de 1797 hasta el de 1850 (París: Imprenta de H. Fournier y compañía, 1841).

37 Lizcano, «Entrevista para el programa del canal TRO...». 
Si bien lo acontecido en Cachirí fue contrario a la causa patriota y a los relatos populares, las generaciones herederas del imaginario heroico promovido por los «libertadores» neogranadinos hicieron posible el reconocimiento simbólico o monumental de cada uno de los acontecimientos independentistas, en particular, la perpetua memoria de los próceres, mártires, caudillos y oficiales distinguidos con la orden de los libertadores. Razón por la cual, el culto a una roca legendaria, la visita a los terrenos que sirvieron de teatro de operaciones, la edificación de monumentos presididos por bustos del «estudiante mártir» ${ }^{38}$ y la conmemoración anual de lo acontecido en su entorno productivo, resultan ser más significativas y convincentes que los relatos atiborrados de datos, estadísticos o interpretaciones por autores foráneos contrarios al sentimiento patriótico ${ }^{39}$.

En el caso de las familias republicanas de Bucaramanga, la inspiración por hacer un homenaje perpetuo al "héroe» de la batalla de Cachirí y la supuesta consigna "firmes Cachirí» se materializó entre 1899 y 1907 con una escultura monumental en la plaza principal de su parroquia natal. La cual se justificó al seguir sus autoridades e intelectuales el influyente y muy consultado "Compendio de la Historia Patria», escrito y promovido desde 1872 por el pedagogo José María Quijano Otero para las escuelas y colegios de todos los Estados Unidos de Colombia. Un texto reeditado en 1910 por la Librería Colombiana con motivo del Centenario de la Independencia Nacional y cuya temática también inspiró y orientó el «Compendio» de J. Henao y G. Arrubla.

La frase "Firmes Cachirí» fue legitimada como verdadera e incuestionable por los académicos, legisladores y gobernantes de Santander al inaugurar el monumento al prócer bumangués en $1907^{40}$, así como al exaltarse a C. García Rovira por su condición de caudillo, mártir y héroe de

38 Cacua Prada, Custodio García Rovira..., 250.

39 Esteban Blanco, "Una nueva mirada a la batalla de Cachirí», en Jornadas de Estudios Históricos: Perspectivas de Colombia y América Latina en el siglo XIX (Bucaramanga: Escuela de Historia UIS, 2017)

40 Cacua Prada, Custodio García Rovira..., 250-252 
la independencia nacional al rendirse honores a su memoria ante el monumento que le recordaba y representaba como digno representante del ethos santandereano ${ }^{41}$ y la grandeza de los primeros bumangueses ilustrados. La consecuencia de ese anacronismo apócrifo se perpetuó entre la memoria popular y la monumentalidad ideológica provincial, de la cual se alimentaron los libros de "lectura moral» e «historia patria" posteriores, al concebirse que el monumento reflejaba la gloria del único diputado, gobernador, general y presidente republicano de la primera república, así como su frase célebre inmortalizaba tanto al héroe como al lugar donde había acontecido una de las batallas fundantes de la campaña libertadora y la defensa del régimen republicano federal.

Siguiendo las interpretaciones del influyente J. Quijano, era necesario que los medios y los mediadores de la instrucción patriótica entre las nuevas generaciones atendieran tanto al rigor científico y las innovaciones didácticas como los efectos morales de cada acontecimiento ${ }^{42}$. La importancia de sucesos como la batalla de Cachirí para la reafirmación del espíritu patriótico y el martirio popular en nombre del régimen republicano debía ser una prioridad para cualquier promotor de la vida republicana, ante lo cual J. Quijano al finalizar la lección XXXVII de su Compendio escribió como una de sus «Indicaciones para los Maestros» la siguiente reflexión didáctica y moral:

Viene de aquella desgraciada batalla la frase que vino a ser proverbio entre los patriotas de 'iFirmes Cachirí!. Estas eran las palabras con que García Rovira exaltaba el entusiasmo de sus soldados, de pie sobre la última trinchera, que defendieron con desesperación. Meses más tarde los pacificadores organizaron un batallón compuesto de los hijos de patriotas, el cual iba siempre destinado al punto más peligroso, y lo llamaron en son de burla: Batallón Cachirí. Cuando estos desgraciados jóvenes eran barridos por las

41 Gobernación de Santander, Centenario de Custodio García Rovira en Bucaramanga, 1816 -8 de agosto- 1916 (Bucaramanga: Taller Gráfico, 1916).

42 Patricia Cardona, «Educar ciudadanos y formar patriotas: libros de historia patria para crear consensos y traspasar las luchas partidistas. Colombia 1850-1886", Araucaria. Revista Iberoamericana de Filosofía, Política y humanidades, $\mathrm{n}^{\circ} 30$ (2013): 63-81. 
balas de sus compatriotas, sobre quienes no hacían fuego, estrechaban las filas y saludaban la muerte con el grito de ¡Firmes Cachirí! ${ }^{43}$.

Las insistentes razones promovidas en el relato de J. Quijano fueron consideradas en una de las placas del monumento a C. García Rovira en el parque principal de Bucaramanga, el cual fue adoptado y replicado por las autoridades de Suratá décadas después. Para ello, los alcaldes y concejales de la época ordenaron que en la plaza principal del corregimiento de Cachirí debía ser construida y erigida una copia de la placa alegórica que hacía parte del monumento bumangués, así como un busto figurativo del General C. García Rovira. Siendo complementado el recuerdo monumental por ese prócer y sus hazañas heroicas con las enseñanzas escolares y las versiones populares de los ancianos y líderes comunales, al exaltar las bondades y particularidades de lugares como la vereda Cachirí.

Ejemplo de esas formas narrativas de la memoria popular que han sido adoptadas y reconstruidas por los campesinos cachirienses es la versión histórica de lo acontecido en 1816 por el líder comunal José Lizcano, la cual fue divulgada a todo el país trasmitida por el programa televisivo de la Gobernación de Santander «Marcando Pasos»" . Durante una de las emisiones televisivas de ese programa, editado y financiado por la gobernación departamental, fueron legitimadas y promovidas.

Incuestionables las versiones híbridas y anacrónicas acerca de lo acontecido en el suelo natal de los cachirienses, apelando para ello a una combinación de los sucesos más emblemáticos de la historia patria de la nación colombiana entre 1816 y 1822 , a saber:

En esta piedra, el 23 de febrero de 1822, el general Custodio García Rovira subió y al terminar la batalla, en retirada

43 José María Quijano Otero, Compendio de la Historia Patria, Segunda edición revisada y corregida por el autor (Bogotá: Imprenta de Medardo Rivas, 1883), 251.

44 Raíces del Gran Santander, transmitido por el Canal de Televisión Regional del Oriente (TRO). 
los españoles, Barreiro ordenó el aviso de trompeta para alejarse, dándose por perdido. Los soldados de Custodio García Rovira al escuchar la trompeta huyeron también. Creyeron que eran los perdedores. De todas formas, aquí en este sector fue esa batalla. Donde ambos ejércitos, que tienen muchos soldados, al huir los soldados de García Rovira... García Rovira se subió en esta piedra y les grita: "Firmes (...) [silenciado: ¿Gran carajos?], siempre adelantes, para atrás ni un paso" (...) Siguió Custodio García Rovira hasta Matanza. Ahí en Matanza se lo alcanzó otra vez Barreiro y lo acabó. Solamente le quedaron trece soldados a Custodio García Rovira, que fueron los que reforzaron el ejército para la batalla en el pantano de Vargas ${ }^{45}$.

Lizcano confundía así los hechos de la Batalla de 1816 con una fecha posterior (1822) al nacimiento de la República, así como desconocía quién era el comandante de la división española vencedora del Ejército de la Unión en Cachirí (S. Calzada), optó por mencionar el emblemático nombre del comandante vencido en la batalla de Boyacá por S. Bolívar (J. Barreiro), tres años después. Así mismo, asumió que el comandante español persiguió y combatió en persona a los combatientes que huían hacia la parroquia de Matanza, cometiendo así los realistas (peninsulares y venezolanos) una nueva matanza ya no contra los indios insurrectos sino contra los patriotas traidores que se resistían a ser reconquistados.

Valga destacar que tanto en el relato oficial del vencedor como en el discurso del vencido se establece que la mayor parte de los caídos murieron cazados mientras huían al abandonar desesperados las trincheras, otros fueron atrapados ocultos entre los bosques, cuevas y quebradas cercanas siendo pasados por las armas. Con lo cual, los únicos que pudieron huir fueron los oficiales que pudieron llegar hasta los caballos dispuestos para su traslado desde Piedecuesta. Constituyéndose ese manto de duda sobre la valentía, experticia y liderazgo de C. García Rovira, F. Santander y el resto de la docena de oficiales que llegaron vivos a El Socorro, uno de los temas más recurrentes en la vida republicana de los siguientes años ${ }^{46}$.

45 Lizcano, «Entrevista para el programa del canal TRO...».

46 Restrepo, Historia de la Revolución..., 391-392. 


\section{Justificaciones desde el relato fundacional de la República de Colombia}

La versión histórica de los cachirienses sobre lo acontecido en su territorio rural en 1816 no siempre ha sido la misma al existir relatos de testigos directos que han validado las versiones oficiales y a los relatos nacionalistas tanto de J. Restrepo como de J. Quijano.

En 1850, al pasar por Cachirí los miembros de la Comisión Corográfica se comprobó que los factores climáticos, de aprovisionamientos y experticia militar habían sido mucho más relevantes que una piedra simbólica, de la cual no dieron cuenta ni resaltaron su existencia los campesinos que habitaban para ese entonces aquel sitio ni tampoco aquellos ancianos que habían sido testigos directos de lo acontecido.

La batalla principal había sucedido en el cerro y «paramillo» de la botija, el cual hacía parte de las bifurcaciones del "camino de la carrera". Siendo descrito el panorama tétrico de ese lugar a todos los neogranadinos de mediados del siglo XIX al relatar M. Ancízar que era un: "camino desierto, enfadoso, batido por ventarrones glaciales que en la estación de las lluvias son insoportables, peligrando la vida de los transeúntes y de las recuas» ${ }^{47}$. Así mismo, los labriegos ancianos que habían sido testigos de lo acontecido manifestaron a los comisionados que quienes habían huido de la matanza de los tres mil neogranadinos en el cerro habían sido aquellos soldados y oficiales a caballo que habían permanecido cómodos junto a la ribera del pedregoso río Cáchira, gozando de aguas, pastos abundantes, una casa que servía de cuartel y un camino seguro hacia el sur, el cual garantizó el rápido escape de los comandantes republicanos.

El contraste entre los diferentes lugares donde aconteció la batalla fue recreado por el pintor de la comisión, el venezolano Carmelo Fernández, quien retrató sus vivencias

47 Manuel Ancízar, Peregrinación de Alpha por las provincias del norte de la Nueva Granada, en 1850 i 1851. (Bogotá: Biblioteca de la Presidencia de la República, 1956), Cap. XXXII, 379. 
y las de los testigos de la batalla de Cachirí por medio de dos acuarelas en las cuales se exaltaba con gran detalle y realismo las condiciones climáticas que se vivían en ese páramo. En la primera de ellas se recrearon las favorables condiciones de la casa que servía de posada y "venta" de suministros para los viajeros, comerciantes, militares, arrieros, etc. que se trasladaban desde los valles de Bucaramanga y Cúcuta a los de Ocaña, y de allí hasta las riberas del Magdalena. Casa de la cual los cachirienses que la habitaban les informaron que: "Treinta y cuatro años antes, por el mes de febrero, fueron los alrededores de aquella casa teatro de adversidades para los granadinos republicanos» ${ }^{48}$.

Para apaciguar todo discurso de desprecio y deshonra al sacrificio de los patriotas caído en Cachirí, Manuel Ancízar optó por sobrevalorar a los mártires-héroes para ocultar o minimizar los errores militares de los generales-presidentes que estuvieron a cargo de la primera y segunda república. Para ello apeló a sentimientos patrióticos y nacionalistas como los siguientes: "La tierra granadina recibió con gratitud la sangre de estos sus buenos hijos; desde entonces se hizo imposible que la tiranía la hollase por largo tiempo» ${ }^{49}$. Así mismo, logró corroborar que la versión de lo sucedido por J. Restrepo en su «Historia», a partir de los testimonios, partes militares y memorias de los oficiales que estuvieron combatiendo en la batalla, coincidía con los relatos de los cachirienses que los habían hospedado antes de continuar su viaje hacia Ocaña.

De allí que siguiendo las versiones de la historia oficial y la de sus contertulios de Cachirí expresara en su informe corográfico que las causas de la derrota patriota en esa batalla se justificaban esencialmente por las siguientes razones:

Los republicanos, en número de 2.500 reclutas, que no tuvieron tiempo de disciplinar en Piedecuesta el general Rovira y el coronel Santander, que los mandaban, se dirigieron al encuentro de los realistas con la esperanza de desbaratarlos antes de que fueran auxiliados por los

48 Ancízar, Peregrinación..., Cap. XXXII, 380.

49 Ancízar, Peregrinación..., Cap. XXXII, 412. 
expedicionarios españoles, dueños del Magdalena y la costa. No esperó Calzada el ataque, sino que levantando el campo atravesó el páramo de Cachirí y se situó en Ramírez. El jefe granadino, desvanecido con la derrota de un cuerpo de observación que el enemigo había dejado en el páramo, debilitó sus fuerzas enviando destacamentos a Pamplona y Cúcuta, en términos de quedarse con poco más de mil hombres, cuando las de su contrario acababan de recibir considerable aumento; contramarcharon éstas, y sorprendiendo a Rovira en las casas de Cachirí, donde vanamente intentó defenderse apoyado en el cerro de Botija, lo derrotaron tan de veras, que apenas 30 hombres reunidos llegaron prófugos a Matanza ${ }^{50}$.

Las descripciones históricas y las recreaciones pictóricas de los miembros de la Comisión Corográfica a la par de servir como instrumento de reconocimiento y redescubrimiento del territorio como de la historia de las provincias que conformaban la Confederación Granadina, contribuyeron a confirmar los relatos y las versiones históricas sobre lo acontecido durante la Campaña Libertadora. En especial, el relato "bolivarista» de lo acontecido después de la caída de la Unión en Cachirí a partir de la versión cronística, documentada y sistemática que caracterizó la perspectiva «oficial» promovida por los gobernantes y ministros leales al primer General, Libertador y Presidente de Colombia. Siendo de destacar el relato oficial compilado en la «Historia de la revolución de la República de Colombia» (París, 1824-1827) por José Manuel Restrepo Vélez (1781-1863), desde su inobjetable condición como testigo de los hechos al ejercer funciones como diputado y gobernador provincial, constitucionalista, magistrado y Secretario de Estado durante la primera y la segunda república neogranadina.

Los testimonios obtenidos por M. Ancízar de gentes comunes, letradas y con funciones públicas a su paso por lugares como Cachirí le permitían reivindicar la crisis en que se encontraba la Unión a inicios de 1816, los errores estratégicos y el exceso de confianza en las tácticas que siguieron los generales republicanos elegidos por el gobierno federal desde Santafé para defender la frontera norte y oriente del país,

50 Ancízar, Peregrinación..., Cap. XXXII, 379-380. 
así como las prácticas y defectos políticos heredados hasta las reformas de mediados del siglo XIX, cuya consecuencia inmediata habían sido las derrotas consecutivas de los Ejércitos de la Unión de la ciudad 'fortificada' de Cartagena, el 'páramo' de Cachirí y la 'cuchilla' de El Tambo.

En estas derrotas gubernamentales y militares estuvo directamente comprometido C. García Rovira como miembro del triunvirato neogranadino y general responsable de los ejércitos al sur y al norte de la República. Su corta pero exitosa carrera como gobernante político y militar del Socorro lo condicionó a asumir la defensa y gobierno de las provincias del Norte ante la derrota a manos de la Quinta División de S. Calzada de los Generales y la Divisiones de la Unión, encargadas de la defensa de las provincias de Pamplona y Ocaña ${ }^{51}$.

Con los restos de las tropas que sobrevivieron a los enfrentamientos con la división realista que ascendió victoriosa y fortalecida de los llanos del Apure, las cuadrillas que lograron huir de la avanzada de Morillo desde Santa Marta, el batallón de reserva conformado con cuatro mil reclutas de la provincia del Socorro y las levas hechas en la provincia de Pamplona, el General C. García Rovira y el coronel F. Santander acataron las órdenes del Gobierno central de la federación en conformar una fuerza capaz de contener la avanzada reconquistadora. Para ello marcharon desde Piedecuesta hacia los páramos que comunicaban a Pamplona con el río Magdalena, cerrando así el paso de la V División en su afán por articular a los batallones que habían avanzado hasta Ocaña, así como para contener el avance medular del Estado Mayor del Ejército Expedicionario al ascender por el río Magdalena, con esta medida avanzaba el resto de las tropas en cada ribera.

Los comandantes patriotas aprovechando el poder que representaba su fuerza compuesta por "dos mil quinientos soldados, los mil seiscientos fusileros con poco más de

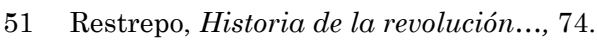


cien jinetes, y el resto armados de lanzas» ${ }^{52}$, asumieron la responsabilidad de contener la avanzada escalonada de P. Morillo, y en particular, en justificar con su sacrificio la extinción de los excesos morales que se cometían por causa de la inacción de los republicanos en la defensa de sus propios credos y pueblos. Excesos que J. Restrepo interpretó como prácticas propias de un ejército invasor que desde sus cuarteles iba: "arruinando las fortunas de todos los vecinos principales; pero lisonjeando y atrayéndose la masa del pueblo, especialmente a los indios que por lo general han sido enemigos de la independencia ${ }^{53}$.

Ese movimiento del ejército republicano «más pronto de lo que hubiera convenido» ${ }^{54}$ justificó a su vez las causas de su derrota militar, y consigo, la pérdida de toda resistencia o posición de contención en las provincias de Girón, Pamplona y El Socorro. Conveniencia que M. Ancízar y los demás estrategas militares de 1850 asociaban con la imperiosa necesidad que se tenía de material de campaña para la alta montaña, así como combatientes disciplinados capaces de soportar las adversidades de los gélidos y ventosos páramos. Así mismo, la prematura victoria de los veteranos de F. Santander sobre un destacamento de trescientos realistas que custodiaban desde una colina el paso por Cachirí (8 febrero de 1816) hacia Pamplona, acrecentó los ánimos triunfalistas sobre el enemigo que marchaba estratégicamente hacia Ocaña, renunciaron a perseguirlo y derrotarlo al temer perder la posición ganada, así como optaron por asentar el cuartel general en un estrecho paramuno a la espera de los bienes de intendencia necesarios para poder combatir. Los cuales debían llegar desde las provincias del interior, acorde a las tardías órdenes del Gobierno Supremo en Santafé.

Con un ejército fortalecido con más combatientes llegados desde el cuartel de Mompox, aunado a los pertrechos necesarios para una campaña de alta montaña, los realistas

52 Restrepo, Historia de la revolución..., 75.

53 Restrepo, Historia de la revolución..., 95.

54 Restrepo, Historia de la Revolución..., 389. 
sorprendieron en su contramarcha a los independentistas al resguardar su avanzada entre la neblina mañanera. Al mediodía del 21 de febrero «dos mil cien fusileros, una compañía de carabineros de a caballo y una pieza de artillería montada» se presentaron frente a los puestos republicanos y los atacaron de forma incesante durante la tarde. El descanso que se dio durante la noche fue aprovechado de forma desesperada por C. García Rovira para apelar a una estrategia militar francesa aprendida en sus libros de estudio sobre las grandes batallas y los grandes generales, con la cual reafirmó de forma excesiva su confianza en los hombres que había entrenado, así como pretendía demostrar con honor militar su condición de General y su pericia como Comandante General de la República.

Para su desdicha, los realistas veteranos habían combatido el sistema de barricadas y trincheras francesas durante las guerras napoleónicas, motivo por el cual de forma rápida y contundente penetraron los flancos, generaron el mayor terror posible a los jóvenes reclutas con sus cornetas y francotiradores, provocando finalmente la huida desordenada de los diferentes batallones provinciales atrincherados. Posteriormente se dio paso a la crueldad y sevicia realista contra los patriotas al quedar esparcidos en los caminos de ese páramo miles de reclutas socorranos y pamploneses que no habían enfrentado un grupo de guerreros de esas condiciones. De allí que ambos bandos terminaran por reconocer que en el campo de batalla «no se salvaron treinta hombres reunidos» ${ }^{55}$.

\section{Representaciones locales desde el culto monumental bumangués.}

Los más de tres mil muertos en una sola batalla, aunados a los cientos caídos en batallas y escaramuzas previas, los cientos de animales de carga y combate sacrificados en los campos de batalla y la pérdida del parque de guerra más grande con el que pudo contar el primer ejército interprovincial de la Unión, no fueron razones suficientes para que la batalla de Cachirí

55 Restrepo, Historia de la revolución..., 76-78 
tuvieron tanta importancia o resonancia como cualquier otra de las batallas de la Campaña Libertadora.

Los comisionados corográficos realzaron el honor y esfuerzo sobrehumano de los combatientes pero no se apartaron de la interpretación histórica acerca de los errores en estrategia y táctica denunciados por J. M. Restrepo. J. Quijano exaltó en su compendio el heroísmo y sacrificio de los mártires, pero reafirmó el análisis de fuerzas proporcionales y experticia entre combatientes establecida por el mismo J. M. Restrepo. Así mismo, J. Henao y G. Arrubla ${ }^{56}$ en su compendio de 1910 asumieron la batalla de Cachirí como una de las principales causas de la «ruina de la República» ${ }^{57}$, siguiendo así los postulados y argumentos del mismo J. Restrepo.

Para ser fieles al espíritu de pacificación y reconciliación nacional que caracterizó a la conmemoración del primer centenario de la emancipación nacional, Henao y Arrubla se apartaron de las condenas personales contra el ingenioso e inexperto C. García Rovira o contra su segundo, el entonces Coronel F. Santander, quien siendo veterano en la guerra contra los realistas no impidió el desastre al que los llevó su comandante general en Cachirí. Constituyéndose ese acontecimiento en una de las máculas empleadas por los bolivaristas para dudar de la valentía, coraje, disciplina y capacidades militares del líder de los opositores republicanistas, así como para despreciar al caudillo ilustrado de Bucaramanga.

Una las estrategias de reivindicación de Henao y Arrubla con los imaginarios y creencias patrióticas de las élites bumangueses fue publicar desde las primeras ediciones de su versión oficial de la "Historia de Colombia» una fotografía del monumento erigido al prócer en su ciudad natal de Bucaramanga. Estatua de cuerpo entero fundida en Francia gracias a las gestiones de la colonia alemana, cuya instalación

56 Jesús Henao y Gerardo Arrubla, Historia de Colombia para la enseñanza secundaria (Bogotá: Librería Colombiana. Camacho Roldán \& Tamayo, 1920), Tomo II.

57 Henao y Arrubla, Historia de Colombia..., Tomo II, 338. 
e inauguración el 20 de enero de 1907 se hizo durante los años que sirvieron de víspera a los actos de conmemoración del centenario de la emancipación nacional ${ }^{58}$.

Ese monumento adornado por un jardín florido exhibía ante los santandereanos a un general vigoroso, quien portaba en su mano derecha la espada de General, el índice de su mano izquierda indicaba el lugar donde se debía centrar el combate mientras una placa en lo alto recordaba a todo espectador su grito de guerra: ¡Firmes Cachirí! Despertando ese monumento el deseo institucional por rememorar y perpetuar entre los bumangueses su nombre y gestas, como prócer y caudillo de la primera república, así como desde 1916 con motivo del centenario de su fusilamiento, los intelectuales y gobernantes lograron que por medio de actos administrativos y legislativos fuese reconocido tardíamente como mártir y héroe de la independencia. Ejemplo de ello fue el Decreto 262 del 12 de julio de 1916 por medio del cual el Gobernador de Santander Ernesto Valderrama Ordóñez ordenaba la «celebración del centenario de la inmolación de Custodio García Rovira» ${ }^{59}$.

Ese monumento demostraba, en oposición a la versión nacional vergonzante promovida por los académicos bogotanos desde la Academia Colombiana de Historia, que para los intelectuales, políticos y representantes de los linajes más prestantes de Bucaramanga, congregados en el Centro de Historia y en la Academia de Historia de Santander, el heroísmo militar y el martirio patriótico del más destacado de sus beneméritos hijos no podía ser tachado por causa de una derrota como un acto de cobardía o de traición. Por el contrario, se preocuparon por crear y promover un imaginario heroico que relacionara la desgracia del campo de Cachirí con el origen de la futura gloria del campo de Boyacá (huida a los llanos por F. Serrano y formación del ejército libertador); la tragedia y sacrificio de los mártires de 1816 con el germen de la liberación nacional de 1819 (protagonismo de F. P. Santander). Con lo cual, los hechos del pasado cobraban un nuevo sentido

58 Henao y Arrubla, Historia de Colombia..., Tomo II, Capítulo VI, 344-345.

59 Cacua Prada, Custodio García Rovira..., 252. 
cuando eran reinterpretados por los intelectuales locales y los académicos regionales para justificar las conmemoraciones y celebraciones a la memoria de los protagonistas parroquiales y provinciales del pasado, excluidos de las grandes gestas y transformaciones del país ${ }^{60}$.

Las visiones y versiones sobre la utilidad social y cultural que debía tener la historia desde la perspectiva de los académicos constructores de identidad, memoria y orgullo territorial fueron sintetizadas en las representaciones históricas sobre Santander publicadas en las siguientes décadas. A través de las mismas se hizo una síntesis simbólica mediante la cual la generación centenarista buscaba para los santandereanos una posición heroica en el panteón de los mártires de la independencia y la liberación nacional. Sirviendo esa misma reinterpretación del pasado heroico santandereano para expiar y pedir perdón por los excesos de los protagonistas del «Olimpo Radical» y la sevicia revolucionaria contra el enemigo estatal en el campo de Palonegro ${ }^{61}$.

De tal manera, y con motivo del tricentenario de la fundación de Bucaramanga, en los "Fastos Bumangueses» redactados por Enrique Otero D'Acosta para el periódico Vanguardia Liberal, se exaltó la memoria de C. García Rovira sin hacer mención de sus derrotas ni de sus fracasos al expresar del insigne bumangués que:

Bucaramanga es cuna del General Custodio García Rovira, quien alcanzó a compartir en triunvirato la Presidencia de las Provincias Unidas de la Nueva Granada y ocupó el puesto de General en Jefe de las tropas de la Unión terminando su vida en uno de los patíbulos que alzó Morillo en $1816^{62}$.

60 Gabriel Samacá y Sol Calderón, «El Centro de Historia de Santander y la gestión de la memoria regional entre 1934 y 1944: Conmemoraciones centenarias de Eloy Valenzuela, Solon Wilches y Vicente Azuero», Historia Y MEMORIA, n 9 (2014): 119-160.

61 Pérez, Narrativas del último Postconflicto...

62 Enrique Otero, «Faustos Bumangueses,» Anuario Ilustrado de La Vanguardia Liberal, $\mathrm{n}^{\circ}$ 1(1922): 97. 
En esa misma publicación Adolfo León Gómez manifestó sobre la expresión monumental de ese recuerdo atesorado dentro de un jardín florido que: «La estatua del prócer custodio García Rovira-el hijo más preclaro de Bucaramanga-alzándose altiva y enérgica en el centro de la plaza de su nombre, parece hacer a Colombia un vaticinio solemne de paz, de gloria y de bonanza ${ }^{63}$. Una década después, José Manuel Rojas Rueda en su texto de monografías municipales de Santander expresó, al igual que los autores y las publicaciones antecesoras, que: «Bucaramanga se gloria de ser cuna de próceres insignes como Custodio García Rovira, el estudiante mártir y presidente del triunvirato de las Provincias Unidas de la Nueva Granada, general de las tropas de la Unión» ${ }^{64}$.

Pretendiendo sintetizar lo expuesto por sus antecesores y ser objetivo en la interpretación de lo acontecido, José Fulgencio Gutiérrez empleó las mismas fuentes citadas por J. Restrepo, J. Quijano, Henao y Arrubla, en especial los partes de guerra y las memorias de los generales y oficiales españoles. Documentos que fueron rescatados y revalorados un siglo después como evidencia incuestionable de lo acontecido por parte de la Academia de Historia de Santander durante la sesión conmemorativa del bicentenario de la Batalla de Cachiríi ${ }^{65}$, así como una comisión de académicos visitó los sitios de los hechos ${ }^{66}$.

Gutiérrez manifestó en su «reseña histórica del pueblo de Santander» que: «No se salvaron sino García Rovira, Santander, unos veinte oficiales y unos treinta jinetes. "Hasta las ruinas perecieron" habría dicho Lucano». Más adelante continuaba diciendo: «Medio pueblo de Santander se desplazó hacia los Llanos en una desbandada general, como recuerda el doctor Florentino González en sus Memorias. En otra parte

63 Adolfo León Gómez, "Bucaramanga», Anuario Ilustrado de La Vanguardia Liberal, $\mathrm{n}^{\circ} 1$ (1922): 141.

64 José Rojas, Ciudades de Santander (Bogotá: ABC, 1939), 9.

65 Armando Martínez Garnica, Disertación de la sesión ordinaria de la Academia de Historia de Santander: La batalla de Cachirí (Bucaramanga: Academia de Historia de Santander, 2016).

66 Virviescas, «Del grito victorioso...», 4-5. 
dejamos dicho por qué motivo es apócrifa y mentirosa la frase atribuida a García Rovira: "Firmes, Cachiriı ${ }^{67}$. Interpretación histórica que revalidaba la versión centralista promovida e institucionalizada a partir del discurso histórico de J. M. Restrepo, rechazaba el uso anacrónico en placas, proclamas y monumentos de toda gloria o grandeza que ocultaba lo ocurrido bajo el manto del heroísmo o el martirio patriota por parte de los derrotados, así como consideraba improbable e inaceptable cualquier versión popular resultante de vivencias, creencias o tergiversaciones localistas que no fuesen documentadas y ajustadas a la historia oficial.

\section{Conclusión}

La historia nacional republicana de Colombia no ha tenido interés por apropiarse, rememorar, conmemorar y exaltar la batalla de Cachirí (1816), considerado el primer combate de resistencia y liberación de un ejército nacional contra el ejército expedicionario que reestableció el régimen virreinal neogranadino desde 1816 hasta 1819. Si bien fue el combate bélico de un ejército conformado por batallones provenientes de las principales provincias libres del país, que en nombre de la Unión (una república, un gobierno, una constitución, un pueblo) representó el primer ejército nacional neogranadino, así mismo fue la batalla más cuestionada, vergonzosa, destructiva y despreciada por los historiadores, gobernantes y generales de las siguientes generaciones de ciudadanos republicanos.

Sin embargo, la historia oficial divulgada en los artículos, libros y manuales de textos promovida por los académicos capitalinos al dejar de coincidir y ajustarse a la memoria popular de las comunidades provinciales en cuanto a la derrota y fracaso de sus "paisanos» libertador, ha propiciado tergiversaciones locales y contradiscursos regionales que promueven el heroísmo y martirio de los patriotas comprometidos, elevando para ello cantos, placas, estatuas

67 José Fulgencio Gutiérrez, Santander y sus municipios (Bucaramanga: Imprenta del Departamento, 1940), 144. 
y monumentos que perpetuaban su gesta y la interpretación «republicana» y compasiva ante sus fracasos.

Manipulación profundizada por las comunidades campesinas donde acontecieron los hechos bélicos al construir una memoria popular compuesta por mitos, leyendas y anécdotas sobre lo acontecido que contradicen la versión centralista, agregan un carácter superior y divino a los héroes, así como construyen un imaginario fundacional de la República a partir de los acontecimientos vivenciados desde su propio entorno productivo.

Esos imaginarios y representaciones en lo concerniente al General C. García Rovira y su gesta en Cachirí al no ajustarse a lo informado por los comandantes de los ejércitos que se enfrentaron ni a las vivencias de las gentes de Cachirí que presenciaron la "carnicería" española sobre los inexpertos soldados neogranadinos del Ejército del Norte, han justificado su existencia y predominio entre las gentes comunes y letradas de Bucaramanga y Santander al crearse un mito patriótico a través de estatuas, monumentos, fiestas patrióticas, nombramiento de lugares y obras públicas con los nombres del prócer santandereano. Así mismo, a través de estrategias propias de la instrucción pública para las nuevas generaciones, de forma periódica se ha dispuesto prolongar la leyenda del primer héroe y mártir bumangués al publicarse nuevos productos didácticos asociados con la biografía, imágenes pictóricas, creaciones literarias, manuales de texto escolar, e incluso, la inauguración de edificios y espacios públicos con el nombre del mártir.

Así, a lo largo de los siglos XIX y XX los diferentes relatos y discursos históricos sobre los acontecimientos bélicos de los insurgentes republicanos pretendieron exaltar y perpetuar la importancia de las batallas en los procesos de transformación del sistema político primigenio (del federalismo civil al centralismo militarista), la adopción de una estrategia militar soberana contra el imperio español (de batallones provinciales a un ejército nacional), así como para rememorar y resignificar la memoria de personajes como C. García Rovira, quien 
siendo caudillo, diputado, general y presidente desconocido o menospreciado por el resto de los colombianos fue exaltado con el centenario y el bicentenario de su martirio como uno de los próceres, héroes y libertadores más ilustres. Revisión histórica con la que se tergiversó el hecho de ser purificado con el fusilamiento de espaldas y la suspensión de sus restos en la horca por alborotador, rebelde, infidente y «estudiante - de General» de los insurgentes durante el tiempo de la revolución y el gobierno independiente.

\section{Fuentes documentales}

Ancízar, Manuel. Peregrinación de Alpha por las provincias del norte de la Nueva Granada, en 1850 i 1851. Bogotá: Biblioteca de la Presidencia de la República, 1956.

Baralt, Rafael María. y Ramón Díaz. Resumen de la historia de Venezuela desde el año de 1797 hasta el de 1850. París: Imprenta de H. Fournier y compañía, 1841.

Gobernación de Santander. Centenario de Custodio García Rovira en Bucaramanga, 1816 -8 de agosto- 1916. Bucaramanga: Taller Gráfico, 1916.

Gutiérrez, José Fulgencio. Santander y sus municipios. Bucaramanga: Imprenta del Departamento, 1940.

Henao, Jesús. y Gerardo Arrubla. Historia de Colombia para la enseñanza secundaria. Bogotá: Librería Colombiana. Camacho Roldán \& Tamayo, 1920.

León Gómez, Adolfo. "Bucaramanga». Anuario Ilustrado de La Vanguardia Liberal, $\mathrm{n}^{\circ}$ 1: (1922): 141.

Lizcano, José. "Entrevista para el programa del canal TRO: Marcando Pasos (2010)». Acceso el 13 de abril de 2016, https:// www.youtube.com/watch? $v=a N g B 0-S S l x g$

Otero, Enrique. "Faustos Bumangueses». Anuario Ilustrado de La Vanguardia Liberal, $\mathrm{n}^{\circ} 1$ (1922): 83-97. 
Quijano Otero, José María. Compendio de la Historia Patria, Segunda edición revisada y corregida por el autor. Bogotá: Imprenta de Medardo Rivas, 1883.

Restrepo, José Manuel. Historia de la Revolución de República de Colombia en la América Meridional. Besanzon: Imprenta de José Jacquin, 1858.

Rojas, José. Ciudades de Santander. Bogotá: ABC, 1939.

\section{Bibliografía}

Acevedo, Álvaro. y Carlos Villamizar. «El último Bolívar: renuncia y retiro del ejercicio del poder (1829-1830) entre la autoridad y la legalidad». Historia Y MEMORIA, n 11 (2015): 213-239.

Arenas, Emilio. La Guaneña La epopeya del Estado Libre e Independiente del Socorro. Bucaramanga: El libro total, 2010.

Blanco, Esteban «Una nueva mirada a la batalla de Cachirí». Jornadas de Estudios Históricos: Perspectivas de Colombia y América Latina en el siglo XIX. Bucaramanga: Escuela de Historia UIS, 2017.

Cacua Prada, Antonio. Custodio García Rovira El estudiante mártir. Bogotá: Plaza \& Janés, 1983.

Cardona, Alba. «Memoria, palabra y acción: La historia patria, un saber para el sentimiento». Anuario de historia regional y de las fronteras $21, \mathrm{n}^{\circ} 2$ (2016): 19-45.

Cardona, Patricia. «Educar ciudadanos y formar patriotas: libros de historia patria para crear consensos y traspasar las luchas partidistas. Colombia 1850-1886». Araucaria. Revista Iberoamericana de Filosofía, Política y humanidades, $\mathrm{n}^{\circ} 30$ (2013): 63-81.

Castiblanco, Andrés. «El bicentenario en Colombia. Memoria, patrimonio y territorio». Historia Y MEMORIA, $\mathrm{n}^{\circ} 1$ (2010): 113-133. 
Cuño, Justo. «Lo real y lo imaginario en la construcción en la primera etapa de la República colombiana». Historia Y MEMORIA, $\mathrm{n}^{\circ}$ 2 (2011): 33-52.

Earle, Rebecca. Spain and the Independence of Colombia, 18101825. Chicago: University of Exeter Press, 1999.

Fontana, Josep. «En torno al significado de la independencia». Historia Y MEMORIA, $\mathrm{n}^{\circ} 2$ (2011): 11-32.

Guacaneme, Manuel. «iFirmes Cachirí! (2013)». Acceso el 13 de abril de 2016, https://www.youtube.com /watch?v=F1PMJtABk7k

Martínez Martín, Abel Fernando. y Andrés Ricardo Otálora. "Antonio Ricaurte. La creación de la imagen de un héroe niño 1830-1881». Historia Y MEMORIA, n 4 (2012): 13-44.

Martínez Martín, Abel Fernando. y Andrés Ricardo Otálora. «Patria y Madre Patria. Las fiestas centenarias de 1910 y 1911 en Tunja». Historia Y MEMORIA, n 5 (2012): 115-143.

Martínez Garnica, Armando. «José Joaquín Camacho y su influencia en la Constitución de la Provincia de Tunja (1811)». Historia Y MEMORIA, n 5 (2012): 73-111.

Martínez Garnica, Armando. Disertación de la sesión ordinaria de la Academia de Historia de Santander: La batalla de Cachirí. Bucaramanga: Academia de Historia de Santander, 2016.

Monsalvo, Edwin. «Ciudadanía, vecindad y sufragio en Cartagena 1810-1834». Historia Y MEMORIA, n 6 (2013): 171-204.

Pagés, Joan. y Edda Sant. «PPor qué las mujeres son invisibles en la enseñanza de la historia?» Historia Y MEMORIA, n 3 (2011): 129-146.

Pérez, Luis. «¿Qué dejó a la historiografía regional el Bicentenario de la Independencia de Colombia? La resignificación del Socorro y los socorranos». Anuario de Historia Regional y de las Fronteras 16, n 1 (2011): 331-352.

Pérez, Luis. «El General José Santos: Héroe y villano de la Regeneración». En Una familia Santos de Santander y 
Colombia, coordinado por Armando Martínez. Bucaramanga: El libro total, 2013.

Pérez, Luis. «El papel bicentenario de los textos escolares en la enseñanza del día de la independencia». Revista Docencia Universitaria 9, $\mathrm{n}^{\circ} 2$ (2011): 125-144.

Pérez, Luis. Giros historiográficos sobre la Historia [Turística] del Socorro. Bucaramanga: L. R. Pérez Pinzón, 2015.

Pérez, Luis. Historia bicentenaria de un día de revolución. Bucaramanga: Universidad Industrial de Santander, 2007.

Pérez, Luis. Historiar la muerte II. Representaciones sociopolíticas sobre el buen "morir por la patria" entre los revolucionarios de Colombia. Bucaramanga: Universidad Industrial de Santander, 2013.

Pérez, Luis. Narrativas del último Postconflicto en Colombia. Antología literaria de la Guerra de los Mil Días (1899-1902). Bucaramanga: L. R. Pérez Pinzón, 2015.

Pita, Roger. "El consumo de bebidas embriagantes durante el proceso de Independencia de Colombia; aliento, festejo y conspiración». Historia Y MEMORIA, n 7 (2013): 227-268.

Robayo, Juan Manuel. «Reflexiones en torno al impacto de la Patria Boba. La independencia de Tunja y su provincia 1810- 1815». Historia Y MEMORIA, $\mathrm{n}^{\circ} 1$ (2010): 11-33.

Samacá, Gabriel. y Sol Calderón. «El Centro de Historia de Santander y la gestión de la memoria regional entre 1934 y 1944: Conmemoraciones centenarias de Eloy Valenzuela, Solon Wilches y Vicente Azuero». Historia Y MEMORIA, $\mathrm{n}^{\circ} 9$ (2014): 119-160.

Samudio, Edda. «La experiencia juntista en Mérida (Venezuela) 1808-1811». Historia Y MEMORIA, n 1 (2010): 35-53.

Sarmiento, Álvaro. La batalla perdida. Bucaramanga: El libro total, 2010. 
Uribe Ángel, Jorge Tomás. «Independencia, historia y derecho». Historia Y MEMORIA, n 2 (2011): 125-143.

Uribe Urán, Víctor. «Insurgentes de Provincia: Tunja, Nueva Granada y el Constitucionalismo en el Mundo Hispánico en la década de 1810». Historia Y MEMORIA, n 5 (2012): 17-48.

Valencia, Alonso. «Indígenas, plebe, sectores populares y afrodescendientes en la independencia de la gobernación de Popayán». Historia Y MEMORIA, nº 1 (2010): 87-112.

Virviescas, Pastor. «Del grito victorioso de "¡Firmes Cachirí!" a la caída estrepitosa de un mito santandereano». Periódico 15 Unab, Bucaramanga, 15 de marzo de 2016, 4-5.

\section{Citar este artículo:}

Pérez Pinzón, Luis Rubén. «Tergiversaciones sobre la batalla de Cachirí y el restablecimiento del régimen virreinal neogranadino (1816)». Historia Y MEMORIA, $\mathrm{n}^{\circ} 15$ (2017): 73 105. DOI: https://doi.org/10.19053/20275137.n15.2017.4922 